\title{
Metastatic versus metachronous adenoid cystic carcinoma in the lacrimal gland fossa: a case report
}

Posey PY Wong ${ }^{1,2}$, MBChB; Karen KW Chan ${ }^{1,2}$, MBBS; Winnie CW Chu ${ }^{3}$, FHKCR; Kelvin KL Chong ${ }^{1,2}$, FCOphthHK ${ }^{1}$ Department of Ophthalmology and Visual Sciences, Prince of Wales Hospital, Hong Kong

${ }^{2}$ Department of Ophthalmology and Visual Sciences, The Chinese University of Hong Kong, Hong Kong.

${ }^{3}$ Department of Imaging and Interventional Radiology, Faculty of Medicine, The Prince of Wales Hospital, The Chinese University of Hong Kong, Shatin, Hong Kong

Correspondence and reprint requests:

Dr Kelvin KL Chong, Department of Ophthalmology and Visual Sciences, The Chinese University of Hong Kong, 4/F Hong Kong Eye Hospital, 147K Argyle Street, Kowloon, Hong Kong.Email: chongkamlung@cuhk.edu.hk

\section{Abstract}

A 53-year-old woman presented with a left painless enlarging lacrimal fossa lesion with hypoglobus and choroidal folds. 18 months earlier, she had undergone surgery and chemoradiotherapy for right maxillary sinus adenoid cystic carcinoma. After initial 1.5T magnetic resonance imaging, a double primary of left lacrimal gland adenoid cystic carcinoma with tricompartmental (frontal bone, lacrimal and temporalis fossa) involvement was suspected. However, subsequent high-field multiparametric 3T magnetic resonance imaging suggested a solitary metastasis with a subperiosteal location and an uninvolved lacrimal gland. The solitary metastasis was confirmed intraoperatively and pathologically.

Key words: Carcinoma, adenoid cystic; Lacrimal apparatus;

Multiparametric magnetic resonance imaging

\section{Introduction}

Adenoid cystic carcinoma (ACC) is the most common lacrimal gland epithelial cancer, accounting for up to $60 \%$ of all cases in one series. ${ }^{1}$ Primary tumor excision, exenteration and/or craniofacial resection together with intra-arterial chemotherapy and external beam irradiation are treatment options depending on tumor staging and clinician experience. ${ }^{2,3}$ We herein describe a patient who presented with an expanding solitary subperiosteal metastasis of maxillary sinus ACC mimicking a double primary of contralateral lacrimal gland ACC.

\section{Case presentation}

In December 2019, a 53-year-old woman presented to our hospital with worsening of the left lower visual field loss. In January 2018, she had undergone subtotal maxillectomy, free fibular flap reconstruction, and adjuvant chemoradiotherapy elsewhere for a pT3N0 ACC of the right maxilla. On examination, her left eye had 7-mm proptosis, 3-mm hypoglobus, limited elevation and superotemporal choroidal folds, and a vaguely palpable non-tender swelling over the lacrimal gland fossa. 1.5T magnetic resonance imaging (MRI) of the orbit showed a well-circumscribed, homogenously contrast-enhancing, T1-hyperintense lesion measuring $2.0 \times 1.7 \times 0.8 \mathrm{~cm}$ over the left lacrimal gland fossa, with frontal bone involvement and suspicious contiguous lymphadenopathy (Figure).

In March 2020, 3T MRI showed a $2.4 \times 2.4 \times 1.7 \mathrm{~cm}$ subperiosteally located lesion in the lacrimal gland fossa indenting onto the left globe with interval increase in size. It was slightly T1-hyperintense to the extraocular muscle and lacrimal gland, heterogeneous T2-hyperintense with small cystic component and a higher degree of contrast enhancement. A normal looking lacrimal gland was inferiorly displaced. Bony dehiscence and extension of the lesion into the temporalis fossa was demonstrated (Figure). Positron emission tomography showed additional multiple nodules in bilateral lungs. 


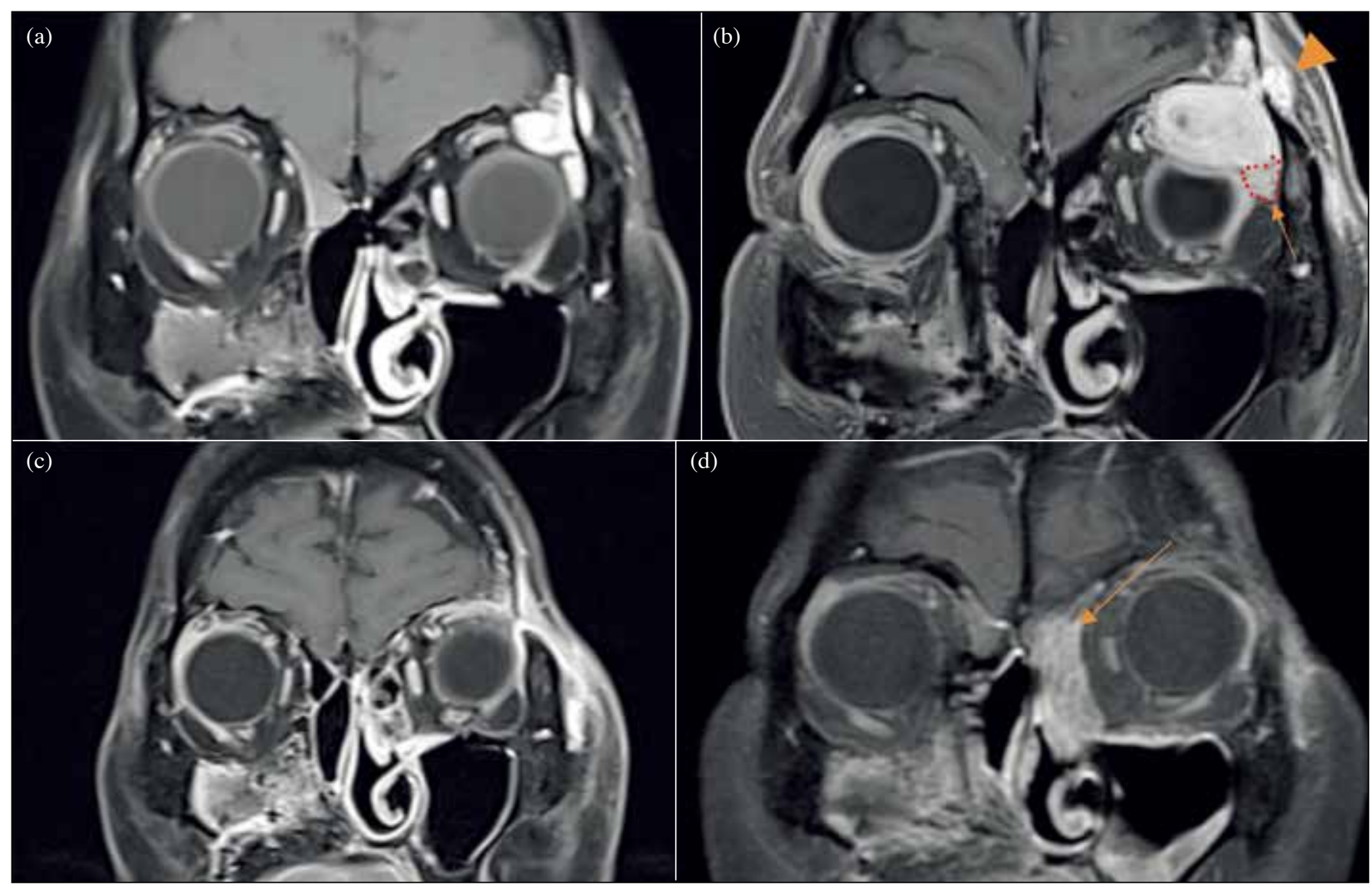

Figure. Post-contrast T1-weighted fat-suppressed coronal magnetic resonance imaging (MRI) of the orbit: (a) In December 2019, 1.5T MRI showing a homogenously contrast-enhancing lesion suspicious of lacrimal fossa tumor over the left lacrimal gland fossa with frontal bone involvement. (b) In March 2020, 3T MRI showing the enlarging lesion and ultra-fine anatomical details, including its subperiosteal location, a small cystic (necrotic) component, normal-looking lacrimal gland displaced inferiorly (arrow), and bony invasion at the frontozygomatic suture extending into the temporalis fossa (arrowhead). (c) In July 2020, 1.5T MRI showing the reduced subperiosteal lesion at 3 months after surgical excision. (d) In December 2020, 1.5T MRI showing no recurrence over the lacrimal fossa at postoperative 7 months, but new enhancing soft tissue (arrow) over the left medial orbit suspicious of metastatic deposit.

In March 2020, the patient underwent left subbrow orbitotomy and excisional biopsy. The subperiosteal location of the tumor, the frontozygomatic bone defect, and normal lacrimal gland were confirmed intraoperatively. She received postoperative adjuvant radiotherapy. In July 2020 and November 2020, postoperative MRI showed no recurrent metastatic disease but suspicious growth over the medial orbit or lacrimal sac region (Figure).

\section{Discussion}

This case illustrates the importance of superior anatomical delineation of complex orbital lesions using high-field 3T MRI, which provides valuable roadmap for pre-operative planning. Multiparametric MRI involves diffusion and perfusion-weighted sequences and provides valuable functional information in addition to anatomical details. ${ }^{4}$ The additional use of diffusion-weighted imaging significantly improves the differentiation of benign from malignant orbital masses..$^{5}$ Substantial enlargement of a noninflammatory lacrimal fossa lesion within a short period together with invasion to the surrounding frontal bone and temporalis fossa was highly suggestive of malignancy. However, on high-field 3T MRI, the subperiosteal location and the normal lacrimal gland concluded that the diagnosis of an advanced primary lacrimal gland ACC was unlikely.

Only one case of metachronous primary ACC has been reported; the patient had a history of an index maxillary sinus ACC with esophageal carcinoma 14 years later. ${ }^{6}$ Whereas there have been 12 cases of lacrimal gland or maxillary sinus ACC with metastasis to other organs including liver, kidneys, and lungs. ${ }^{7-16}$ Therefore, primary versus metachronous ACC are differential diagnoses. High-field multiparametric MRI is an important tool to assess orbital masses.

\section{Author contributions:}

Concept or design: KKLC

Acquisition of data: KKLC, WCWC 
Analysis or interpretation of data: PPYW, KKLC

Drafting of the article: PPYW

Critical revision for important intellectual content: KKWC \& KKLC, WCWC

All authors had full access to the data, contributed to the study, approved the final version for publication, and take responsibility for its accuracy and integrity.

\section{Conflicts of interest}

The authors have no conflicts of interest to disclose.

\section{References}

1. Shields JA, Shields CL, Epstein JA, Scartozzi R, Eagle RC Jr. Review: primary epithelial malignancies of the lacrimal gland: the 2003 Ramon L. Font lecture. Ophthalmic Plast Reconstr Surg 2004;20:10-21. Crossref

2. Tse DT, Kossler AL, Feuer WJ, Benedetto PW. Long-term outcomes of neoadjuvant intra-arterial cytoreductive chemotherapy for lacrimal gland adenoid cystic carcinoma. Ophthalmology 2013;120:1313-23. Crossref

3. Woo KI, Kim YD, Sa HS, Esmaeli B. Current treatment of lacrimal gland carcinoma. Curr Opin Ophthalmol 2016;27:449-56. Crossref

4. Purohit BS, Vargas MI, Ailianou A, et al. Orbital tumours and tumour-like lesions: exploring the armamentarium of multiparametric imaging. Insights Imaging 2016;7:4368. crossref

5. Russo C, Strianese D, Perrotta M, et al. Multi-parametric magnetic resonance imaging characterization of orbital lesions: a triple blind study. Semin Ophthalmol 2020;35:95102. Crossref

6. Chang HY, Jiang H, Zhou F. A rare case of metachronous triple cancers involving the tympanic membrane. Pak J Med Sci 2013;29:218-9. Crossref

7. Blanco M, Garcia-Fontan E, Rios J, Rivo JE, FernandezMartin R, Canizares MA. Pulmonar collision tumor: metastatic adenoid cystic carcinoma and lung adenocarcinoma. Rev Port Pneumol 2012;18:42-5. crossref

8. Lin WY, Hsu WH. Tumor-to-tumor metastasis: maxillary sinus

\section{Funding support}

This research received no specific grant from any funding agency in the public, commercial, or not-for-profit sectors.

\section{Patient consent}

The patient was treated in accordance with the Declaration of Helsinki. The patient provided informed consent for the treatment/procedures. The patient provided consent for publication. adenoid cystic carcinoma metastasizing to double primary lung adenocarcinoma. Ann Thorac Surg 2010;90:e59-61. Crossref

9. Satake $N$, Yoshida S, Jinnouchi $O$, Sekita T. Adenoid cystic carcinoma of maxillary sinus with metastatic hepatocellular carcinoma. Case report. APMIS 2005;113:450-5. crossref

10. Park DY, Lee JH, Suh YL, Woo KI, Kim YD. Metastatic adenoid cystic carcinoma of the eyelid. Ophthalmic Plast Reconstr Surg 2012;28:e111-2. Crossref

11. Jedrych J, Galan A. Multiple cutaneous metastases: a rare and late sequelae of lacrimal gland adenoid cystic carcinoma. J Cutan Pathol 2013;40:341-5. crossref

12. Petrelli RL, Labay GR, Schwarz GS. Adenoid cystic carcinoma with orbital and cranial metastases: case report. Ann Ophthalmol 1978;10:611-5.

13. Kaur A, Harrigan MR, MeKeever PE, Ross DA. Adenoid cystic carcinoma metastatic to the dura: report of two cases. J Neurooncol 1999;44:267-73. Crossref

14. Bacalja J, Magazin M, Ulamec M, Rako D, Trnski D, Kruslin $B$. Adenoid cystic carcinoma of the lacrimal gland metastatic to the kidney: case report and review of the literature. Scott Med J 2014;59:e14-7. Crossref

15. Maamari RN, Custer PL, Harocopos GJ. Incidentally discovered adenoid cystic carcinoma of the lacrimal gland with isolated liver metastases. Ocul Oncol Pathol 2017;3:2626. Crossref

16. Zeidan BA, Abu Hilal M, Al-Gholmy M, El-Mahallawi H, Pearce NW, Primrose JN. Adenoid cystic carcinoma of the lacrimal gland metastasising to the liver: report of a case. World J Surg Oncol 2006;4:66. Crossref 